\title{
Pengaruh Pemberian Air Kelapa (Cocos nucifera. L) pada Media Agar Darah terhadap Pertumbuhan Bakteri Mycobacterium tuberculosis
}

\author{
Maria Nuraeni', Rosnita Sebayang ${ }^{2}$ \\ ${ }^{1,2}$ Fakultas Ilmu Kesehatan, Universitas Katolik Musi Charitas Palembang, Indonesia \\ Email: yuventia@ukmc.ac.id
}

\begin{abstract}
The Effect Of Provision Cocos Nucifera $\mathbf{L}$ on Blood Agar Plate to Mycobacterium tuberculosis Growth. Tuberculosis is still becoming a health problem in Indonesia. High prevalence of Tuberculosis has encouraged efforts so that patients get treatment immediately. The gold standard to diagnose the disease is by performing bacteriae culture. The culture media for Mycobacterium tuberculosis is quite expensive and also takes quite a long period to let the bacteriae grow up. A blood agar plate is a nonselective media enabling the growth almost all bacteriae. Hopefully, the growth of Mycobacterium tuberculosis becomes more rapid by providing coconut water on a blood agar plate. This study was to provide the effects of provision coconut water with the concentration $50 \%, 75 \%$ and $100 \%$ on blood agar plate which were incubated at temperature $35 \mathrm{C}$ and $37 \mathrm{oC}$. This was an experimental study using pure strain Mycobacterium tuberculosis (H37RV). The result of the study showed that Mycobacterium tuberculosis was able to grow up in a blood agar plate with coconut water $100 \%$ concentration which added to the media. Incubation time was 14 days at temperature $35^{\circ} \mathrm{C}$ and $37^{\circ} \mathrm{C}$. Regression logistic test showed a significant value of the concentration, temperature, and duration variable were 0,738 , 0,872 and 0,720 , respectively. There was no effect of coconut water concentration, temperature dan incubation period to the growth of Mycobacterium tuberculosis.
\end{abstract}

Keywords: Mycobacterium tuberculosis, Blood agar plate, Cocos nucifera L.

\begin{abstract}
Abstrak: Pengaruh Pemberian Air Kelapa (Cocos nucifera. L) pada Media Agar Darah terhadap Pertumbuhan Bakteri Mycobacterium tuberculosis. Tuberkulosis masih menjadi masalah kesehatan di Indonesia. Tingginya kasus TB, mendorong upaya agar penderita segera mendapatkan pengobatan. Gold standard untuk menegakkan diagnosis dengan melakukan kultur bakteri. Media kultur Mycobacterium tuberculosis relatif mahal dan membutuhkan waktu yang lama, maka diupayakan media kultur yang relatif lebih murah dan waktu pertumbuhan yang lebih cepat. Base agar darah merupakan media non selektif yang memungkinkan pertumbuhan sebagian besar organisme. Dengan penambahan air kelapa pada base agar darah mendukung pertumbuhan Mycobacterium tuberculosis. Penelitian ini bertujuan mengetahui pengaruh penambahan air kelapa dengan konsentrasi 50\%, 75\% dan 100\% pada media agar darah yang diinkubasi pada suhu $28^{\circ} \mathrm{C}$ dan $37^{\circ} \mathrm{C}$. Jenis penelitian eksperimen menggunakan strain murni Mycobacterium tuberculosis (H37RV). Hasil penelitian menunjukkan Mycobacterium tuberculosis tumbuh pada base agar darah yang ditambahkan air kelapa dengan konsentrasi $100 \%$. Pertumbuhan terjadi dengan lama inkubasi 14 hari pada suhu $28^{\circ} \mathrm{C}$ dan $37^{\circ} \mathrm{C}$. Hasil uji regresi logistik didapatkan nilai sig variabel konsentrasi, suhu dan waktu lebih sebesar dari 0,5 dengan nilai berturut-turut yaitu $0,738,0,872$ dan 0,720 . Tidak ada pengaruh konsentrasi air kelapa, suhu dan waktu inkubasi terhadap pertumbuhan Mycobacterium tuberculosis.
\end{abstract}

Kata kunci: Mycobacterium tuberculosis, Base agar darah, Cocos nucifera $\mathrm{L}$.

Tuberkulosis paru merupakan penyakit infeksi saluran pernapasan yang disebabkan oleh bakteri Mycobacterium tuberculosis. Sampai saat ini TB Paru masih menjadi masalah kesehatan di dunia yang belum terselesaikan. Berdasarkan data dari Kementerian Kesehatan Indonesia tahun 2017, jumlah penderita tuberculosis di Indonesia menduduki peringkat nomor dua di dunia setelah India, dan di Sumatera Selatan jumlah penderita tuberculosis pada tahun 2017 sebanyak 11.107 orang.

Berbagai upaya dilakukan untuk menurunkan jumlah penderita TB paru agar segera mendapatkan pengobatan. Pemeriksaan laboratorium merupakan tahapan yang penting, gold standard untuk penegakan diagnosis TB dengan kultur. Mycobacterium tuberculosis memiliki sifat pertumbuhan yang lambat pada 
media kultur, yaitu 2-6 minggu atau lebih untuk melihat adanya pertumbuhan koloni. Media artifisial untuk isolasi megandung bahan kompleks yaitu telur dan garam-garam. Media biakan Mycobacterium tuberculosis yang banyak digunakan adalah Lowenstein-jenses, Kudoh, dan Ogawa (Sinaga, 2011).

Media kultur Mycobacterium tuberculosis relatif mahal, salah satu media yang relatif lebih murah dan banyak digunakan di laboratorium adalah base agar darah. Media ini mengandung karbohidrat yaitu glukosa yang difermentasi. Base Agar Darah dibuat dengan menambahkan 5\% darah domba ke dalam media untuk isolasi bakteri dan melihat aktivitas hemolitik bakteri Streptococcus (Zimbro, 2009).

Bahan dasar lain untuk media biakan bakteri yang mudah didapatkan adalah air kelapa, Molnár, et al., (2011) menjelaskan bahwa air kelapa dan santan, dapat digunakan sebagai kultur jaringan. Beberapa penelitian terdahulu menunjukkan bahwa air kelapa dapat dimanfaatkan sebagai bahan dasar media pertumbuhan bakteri, antara lain penelitian yang dilakukan oleh Putri, dkk. (2013), hasil penelitian menunjukkan bahwa pemberian air kelapa pada media dengan konsentrasi 3\%, $4 \%$ dan $5 \%$ dapat menumbuhkan mikroalga Tetraselmis sp, dengan kerapatan 54,75.104 sel/ ml. Penelitian lain dilakukan oleh Yolanda dan Mulyana (2011), dengan melakukan isolasi bakteri dari beberapa spesies Enterobacteriaceae dan kokus gram positif menggunakan air kelapa tua yang dikomposisikan menyerupai agar MacConkey dan lempeng agar darah. Media standar yang digunakan adalah agar MacConkey dan lempeng agar darah, untuk menilai gambaran makroskopis dan mikroskopis. Hasil penelitian menunjukkan gambaran spesifik dari bakteri uji seperti koloni berwarna merah, gambaran mukoid, dan zona hemolitik serupa antara media standar dan media air kelapa tua, secara statistik tidak ada perbedaan bermakna.

Tujuan penelitian diketahui pengaruh terhadap pertumbuhan Mycobaterium tuberculosis pada base agar darah yang ditambahkan air kelapa tua dengan konsentrasi $50 \%, 75 \%$ dan $100 \%$ dan diinkubasi pada suhu $28{ }^{\circ} \mathrm{C}$ dan $37{ }^{\circ} \mathrm{C}$. Manfaat dari penelitian ini adalah memberikan informasi ilmiah bagi petugas di layanan laboratorium tentang pemanfaatan air kelapa tua sebagai media alternatif untuk pertumbuhan bakteri Mycobacterium tuberculosis.

\section{METODE}

Penelitian ini merupakan penelitian eksperimental laboratorium. Uji pendahuluan dilakukan di Laboratorium Mikrobiologi Universitas Katolik Musi Charitas Palembang, dan penelitian dilakukan di Balai Besar Laboratorium Kesehatan Palembang, pada bulan Maret s/d Mei 2018, dengan biaya dari Kementerian Riset dan Teknologi Perguruan Tinggi dan Lembaga Layanan Pendidikan Tinggi Wilayah II. Sampel penelitian adalah air kelapa tua Cocos nucifera $L$ yang dijual di pasar Cinde, berumur 48 jam setelah dipetik, yang digunakan sebagai pelarut media agar darah untuk kultur bakteri Micobacterium tuberculosis. Penentuan jumlah sampel secara purposive sampling.

Prosedur pembuatan media Lowenstein Jensen mengacu pada Buku Petunjuk Teknis dari Menteri Kesehatan tahun 2012, tentang pemeriksaan biakan, identifikasi dan uji kepekaan Mycobacterium tuberculosis pada media padat. Pembuatan media dengan cara: menimbang medium dasar LJ sebanyak 18,65 gram, dilarutkan ke dalam $300 \mathrm{ml}$ aquadest, kemudian ditambahkan $6 \mathrm{ml}$ glycerol dan $10 \mathrm{ml}$ larutan malachite green 2\%. Larutan disterilkan menggunakan autoclaved pada suhu $121^{\circ} \mathrm{C}$ selama 30 menit kemudian didinginkan, ditambahkan telur sebanyak $500 \mathrm{ml}$ dan dihomogenkan. Media dimasukkan ke dalam tabung bertutup alur sebanyak 6-8 ml, kemudian dipanaskan pada suhu $85^{\circ} \mathrm{C}$ selama 50 menit.

Pembuatan base agar darah dengan penambahan Air Kelapa tua konsentrasi 50\%, $75 \%$ dan $100 \%$ seperti pada tabel 1. Base agar darah yang telah dibuat, dituangkan ke dalam botol anulir sebanyak 6-8 ml. Untuk mengetahui pertumbuhan Micobakterium tuberkulosis, dilakukan inokulasi menggunakan Strain murni Micobakterium tuberkulosis H37RV, pada media Lowenstein Jensen dan base agar darah dengan pelarut air kelapa konsentrasi 50\%, 75\% dan $100 \%$, yang diinkubasi pada suhu $28^{\circ} \mathrm{C}$ dan $37^{\circ} \mathrm{C}$. Pengamatan dilakukan pada hari ke 2, 7 dan 14. 
Tabel. 1 Pembuatan Base Agar Darah

Base Agar Darah

Base agar darah + air kelapa tua konsentrasi $75 \%$

Base agar darah + air kelapa tua konsentrasi 100\%
Pembuatan Media

- 4 gr base agar darah $+1,25 \mathrm{ml}$ gliserol $+50 \mathrm{ml}$ aquadest $+3,0 \mathrm{ml}$ malachite green $2 \%$

- Sterilisasi 15 menit dengan suhu $121{ }^{\circ} \mathrm{C}$, dinginkan sampai suhu $\pm 50{ }^{0} \mathrm{C}$

- Tambahkan $50 \mathrm{ml}$ air kelapa tua ke conical flask steril $+7 \mathrm{ml}$ darah domba dan dihomogenkan

- 4 gr base agar darah $+1,25 \mathrm{ml}$ gliserol $+25 \mathrm{ml}$ aquadest $+3,0 \mathrm{ml}$ malachite green $2 \%$

- Sterilisasi 15 menit dengan suhu $121{ }^{\circ} \mathrm{C}$, dinginkan sampai suhu $\pm 50{ }^{\circ} \mathrm{C}$

- Tambahkan $75 \mathrm{ml}$ air kelapa ke conical flask steril $+75 \mathrm{ml}$ air kelapa tua $+7 \mathrm{ml}$ darah domba dan dihomogen-kan

- 4 gr base agar darah $+1,25 \mathrm{ml}$ gliserol $+20 \mathrm{ml}$ aquades $+3,0$ malachite green $2 \%$

- Sterilisasi selama 15 menit dengan suhu $121{ }^{0} \mathrm{C}$, dinginkan sampai suhu $\pm 50{ }^{\circ} \mathrm{C}$

- Tambahkan $100 \mathrm{ml}$ air kelapa tua ke conical flask steril $+7 \mathrm{ml}$ darah domba dan dihomogenkan

Untuk mengetahui apakah pertumbuhan mycobacterium tuberculosis pada media base agar darah dipengaruhi oleh penambahan air kelapa tua berbagai konsentrasi, suhu inkubasi, dan lama inkubasi, data penelitian dianalisis secara statistik menggunakan uji regresi logistik.

HASIL

Strain murni Mycobacterium tuberculosis, yang dipakai dalam penelitian terlebih dahulu diperiksa secara mikroskopis dengan pewarnaan Zielh Nelseen. Hasil pewarnaan adalah bakteri tahan asam berbentuk batang berwarna merah. Hasil uji sterilitas media Bases Agar Darah dan Lowenstein Jensen, diketahui tidak terdapat pertumbuhan mikroorganisme pada kedua media tersebut. Pertumbuhan koloni Mycobacterium tuberculosis pada media Lowenstein Jensen dan Bases Agar Darah, yang diinkubasi pada suhu $28^{\circ} \mathrm{C}$ dan $37^{\circ} \mathrm{C}$, seperti pada tabel 2 .
Tabel 2. Pertumbuhan tuberculosis

\begin{tabular}{|c|c|c|c|}
\hline Media & $\begin{array}{l}\text { Suhu } \\
\text { Inku- } \\
\text { basi }\end{array}$ & $\begin{array}{c}\text { Waktu } \\
\text { Inkubasi }\end{array}$ & $\begin{array}{c}\text { Pertumbuhan } \\
\text { Micobacterium } \\
\text { tuberculosis }\end{array}$ \\
\hline \multirow{6}{*}{$\mathrm{LJ}$} & $28{ }^{0} \mathrm{C}$ & 2 hari & Tidak tumbuh \\
\hline & & 7 hari & Tidak tumbuh \\
\hline & & 14 hari & Tumbuh \\
\hline & $37{ }^{0} \mathrm{C}$ & 2 hari & Tidak tumbuh \\
\hline & & 7 hari & Tidak tumbuh \\
\hline & & 14 hari & Tumbuh \\
\hline \multirow{6}{*}{$\begin{array}{l}\mathrm{BA}+ \\
\text { air } \\
\text { kelapa } \\
50 \%\end{array}$} & $28{ }^{0} \mathrm{C}$ & 2 hari & Tidak tumbuh \\
\hline & & 7 hari & Kontaminasi \\
\hline & & 14 hari & Tidak tumbuh \\
\hline & $37{ }^{0} \mathrm{C}$ & 2 hari & Tidak tumbuh \\
\hline & & 7 hari & Tidak tumbuh \\
\hline & & 14 hari & Tidak tumbuh \\
\hline \multirow{6}{*}{$\begin{array}{l}\mathrm{BA}+ \\
\text { air } \\
\text { kelapa } \\
75 \%\end{array}$} & $28{ }^{0} \mathrm{C}$ & 2 hari & Tidak tumbuh \\
\hline & & 7 hari & Tidak tumbuh \\
\hline & & 14 hari & Tidak tumbuh \\
\hline & $37{ }^{0} \mathrm{C}$ & 2 hari & Tidak tumbuh \\
\hline & & 7 hari & Tidak tumbuh \\
\hline & & 14 hari & Tidak tumbuh \\
\hline \multirow{6}{*}{$\begin{array}{l}\mathrm{BA}+ \\
\text { air } \\
\text { kelapa } \\
100 \%\end{array}$} & $28{ }^{0} \mathrm{C}$ & 2 hari & Tidak tumbuh \\
\hline & & 7 hari & Tidak tumbuh \\
\hline & & 14 hari & Tumbuh \\
\hline & $37{ }^{0} \mathrm{C}$ & 2 hari & Tidak tumbuh \\
\hline & & 7 hari & Tidak tumbuh \\
\hline & & 14 hari & Tumbuh \\
\hline
\end{tabular}

Dari hasil penelitian diketahui pertumbuhan koloni Mycobacterium tuberculosis 
pada media Lowenstein Jensen dan base agar darah yang ditambahkan air kelapa tua konsentrasi $100 \%$ terjadi pada hari ke 14 , baik yang diinkubasi pada suhu $28^{\circ} \mathrm{C}$ maupun pada suhu $37^{\circ} \mathrm{C}$. Pertumbuhan koloni Mycobacterium tuberculosis pada media Lowenstein Jensen dan base agar darah seperti pada gambar 1 dan 2.

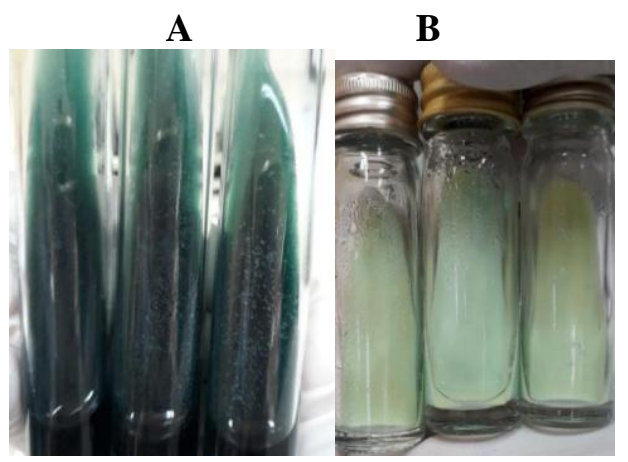

Gambar 1. A. Koloni Mycobacterium tuberculosis di Base agar darah yang ditambahkan air kelapa $100 \%$; B. Koloni Mycobacterium tuberculosis pada Lowenstein Jensen dengan suhu inkubasi $28^{0} \mathrm{C}$

A

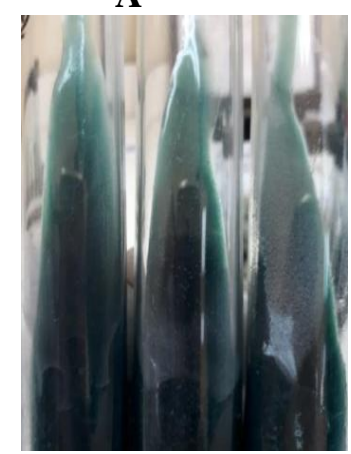

Gambar 2. A Koloni

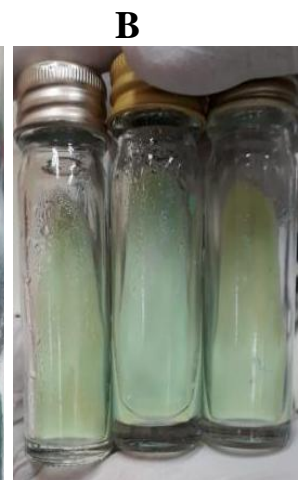

Mycobacterium tuberculosis di Base agar darah yang ditambahkan air kelapa 100\%; B. Koloni Mycobacterium tuberculosis pada Lowenstein Jensen dengan suhu inkubasi 37 ${ }^{0} \mathrm{C}$

Hasil uji regresi logistik diketahui variabel konsentrasi, dengan nilai sig 0,738 , variabel suhu dengan nilai sig 0,872 dan variabel waktu dengan nilai sig 0,720 . Nilai sig semua variabel bebas lebih besar dari 0,05 maka dapat disimpulkan tidak ada pengaruh konsentrasi air kelapa, suhu dan waktu inkubasi terhadap pertumbuhan Mycobacterium tuberculosis.

\section{PEMBAHASAN}

Koloni Mycobacterium tuberculosis dapat tumbuh pada base agar darah yang ditambahkan air kelapa dengan konsentrasi $100 \%$. Pertumbuhan tampak pada hari ke 14 baik yang diinkubasi pada suhu $28^{\circ} \mathrm{C}$ maupun suhu $37^{\circ} \mathrm{C}$. Mycobacterium tuberculosis dapat tumbuh pada kedua suhu tersebut, karena termasuk dalam golongan bakteri mesofilik. Bakteri mesofil tumbuh optimal pada suhu $20^{0}-40^{\circ} \mathrm{C}$, suhu optimum pertumbuhan bakteri patogen berkisar pada suhu $\quad 37^{\circ} \mathrm{C}$ (Radji, 2016). Mycobacterium tuberculosis bersifat aerob obligat, bakteri tidak dapat hidup apabila tidak terdapat oksigen bebas. Kebanyakan bakteri tumbuh baik pada suhu $35{ }^{\circ} \mathrm{C}$ sampai dengan $37^{\circ} \mathrm{C}$. Bakteri penyebab penyakit dan infeksi pada manusia, adalah bakteri mesofil yang tumbuh pada suhu $24{ }^{\circ} \mathrm{C}$ sampai dengan $40{ }^{\circ} \mathrm{C}$, suhu tersebut merupakan kisaran suhu bagi organisme tumbuh dengan baik, karena enzym berfungsi maksimal (Pollack et al., 2016).

Adanya Pertumbuhan Mycobacterium tuberculosis pada base agar darah yang ditambahkan air kelapa tua menunjukkan bahwa air kelapa dapat dimanfaatkan sebagai bahan dasar media isolasi, karena mengandung unsur yang dibutuhkan untuk pertumbuhan bakteri. Air kelapa memiliki kandungan protein, lemak dan kaya akan karbohidrat sebagai sumber nutrisi untuk bakteri (Munawaroh et al, 2015).

Hasil penelitian ini sejalan dengan penelitian Palange et al., (2016) bahwa base agar darah dapat digunakan untuk isolasi Mycobacterium tuberculosis, dengan melakukan evaluasi media kultur isolasi spesies Micobacterium dari spesimen klinis manusia. Hasil penelitian diketahui bahwa base agar darah merupakan media pertumbuhan yang cepat untuk isolasi Mycobacterium tuberculosis.

Hasil penelitian lain yang dilakukan oleh Yolanda dan Mulyana, (2011) dengan melakukan isolasi bakteri Enterobacteriaceae dan kokus gram positif pada dua media yaitu, media agar bacto $15 \mathrm{~g}$ yang dilarutkan dengan akuades sampai volume satu liter dan media agar bacto $15 \mathrm{~g}$ yang dilarutkan dengan air kelapa tua sampai volume satu liter. Hasil penelitian menunjukkan bahwa pada media agar yang tidak mengandung air kelapa tua, tidak didapatkan pertumbuhan bakteri uji, sedangkan pada media agar dengan penambahan air kelapa tua terdapat pertumbuhan hampir semua bakteri uji, kecuali streptokokus $\beta$ hemolitik.

Penelitian lain yang dilakukan oleh Munawaroh et al., (2015) dengan melakukan 
studi komparasi media kultur Coco Blood Malachite Green (CBM) menggunakan air kelapa muda dan Lowenstein Jensen untuk diagnosa cepat sensitif dan spesifik sputum pasien suspek tuberkulosis, didapatkan hasil media CBM terbukti dapat menumbuhkan koloni lebih cepat, lebih sensitif namun kurang spesifik.

Komposisi base agar darah yang digunakan dalam penelitian ini, terdiri atas air kelapa tua, agar, darah domba, malachite green dan gliserol yang kaya nutrisi. Selain air kelapa tua sebagai sumber nutrisi Mycobacterium tuberculosis, pada base agar darah mengandung nutrient substrat, sodium chloride dan agar sehingga memungkinkan Mycobacterium tuberculosis untuk tumbuh.

Sinaga, (2011) menjelaskan bahwa media artifisial untuk isolasi Mycobacterium tuberculosis mengandung bahan kompleks yaitu telur dan garam-garam. Bakteri membutuhkan unsur karbon, nitrogen, potasium, sodium, magnesium, zink, besi, fosfor dan sulfur. Untuk pertumbuhan, bakteri membutuhkan unsur fisika yaitu suhu, $\mathrm{PH}$, tekanan osmotik dan unsur kimiawi yaitu sumber $\mathrm{C}, \mathrm{N}, \mathrm{S}, \mathrm{P}, \mathrm{O}$, mineral dan faktor pertumbuhan organik (Harti, 2014).

Dalam penelitian ini, pertumbuhan koloni Mycobacterium tuberculosis hanya terjadi pada media base agar darah yang ditambah air kelapa tua dengan konsentrasi $100 \%$, sedangkan pada konsentrasi $50 \%$ dan $75 \%$ tidak terdapat pertumbuhan koloni bakteri. Hal ini menunjukkan bahwa air kelapa dengan konsentrasi $100 \%$ memenuhi kebutuhan nutrisi bakteri Mycobacterium tuberculosis. Menurut Soedarto (2015), Pertumbuhan maksimal terjadi jika kondisi medium kultur optimal bagi kehidupan bakteri.

Molnár et al., (2011) menjelaskan bahwa air kelapa dan santan, dapat digunakan sebagai kultur jaringan. Dibandingkan santan, air kelapa memiliki kandungan senyawa yang lebih komplek, yaitu mengandung sejumlah asam amino, asam organik, asam nukleat, beberapa vitamin, gula dan alkohol gula, hormon tanaman (auksin, sitokinin), mineral, dan zat tak dikenal lainnya. Media yang ditambahkan air kelapa dapat menginduksi sel tumbuhan untuk membelah dan tumbuh dengan cepat, hal ini dapat diterapkan sebagai media kultur.

Berdasarkan waktu pertumbuhan, koloni Mycobacterium tuberculosis tumbuh pada base agar darah yang ditambahkan air kelapa tua $100 \%$ pada hari ke 14 demikian juga pertumbuhan pada media Lowestein Jensen. Karakteristik koloni Mycobacterium tuberculosis pada base agar darah yaitu ukuran koloni kecil, kasar warna keabuan dan berkilau dengan latar belakang merah, sedangkan pada media Lowenstein Jensen koloni kassar warna krem, dengan latar belakang hijau kebiruan. Pertumbuhan koloni baru terjadi pada hari ke empatbelas, hal ini disebabkan karena pertumbuhan Mycobacterium tuberculosis sangat lambat, meskipun dibiakkan dalam medium kultur yang diperkaya. Menurut Soedarto (2014), koloni baru terbentuk 4-6 minggu sesudah inkubasi pada sushu $37{ }^{0} \mathrm{C}$, dengan sifat koloni yang kering, keras, tidak mudah meleleh, permukaan koloni tidak teratur dan berwarna gelap. Medium Lowestein Jensen merupakan medium berbasis telur yang mengandung bahan penghambat kontaminan yang mengganggu pertumbuhan.

Hasil penelitian ini berbeda dengan hasil penelitian Munawaroh et al., (2015) yang menggunakan media kultur Lowestein Jensen dan CBM (Coco Blood Malachite green), menggunakan air kelapa muda. Pertumbuhan koloni Mycobacterium tuberculosis pada media CBM tercepat 2 hari dan terlama adalah 6 hari, sedangkan pada media LJ pertumbuhan tercepat adalah 6 hari dan terlama 49 hari. Perbedaan hasil penelitian ini dapat disebabkan karena spesies kelapa dan umur air kelapa yang digunakan berbeda. Adanya pertumbuhan koloni Mycobacterium tuberculosis pada media base agar darah yang ditambahkan air kelapa tua $100 \%$, menunjukkan bahwa media ini memiliki potensi sebagai media alternatif untuk kultur Mycobacterium tuberculosis. Untuk memastikan apakah spesies kelapa dan umur kelapa yang digunakan airnya sebagai bahan dasar media mempengaruhi pertumbuhan bakteri, perlu dilakukan penelitian lebih lanjut.

\section{SIMPULAN}

Terdapat pertumbuhan koloni Mycobacterium tuberculosis pada media Lowestein Jensen dan base agar darah yang ditambahkan air kelapa konsentrasi $100 \%$, dengan suhu inkubasi $35{ }^{\circ} \mathrm{C}$ dan $37{ }^{\circ} \mathrm{C}$. Koloni Mycobacterium tuberculosis tumbuh pada media base agar darah dan Lowestein Jensen pada hari ke empatbelas. 


\section{SARAN}

Air kelapa memiliki potensi sebagai media pertumbuhan bakteri Mycobacterium tuberculosis. Untuk mengetahui apakah jenis kelapa berpengaruh terhadap pertumbuhan perlu dilakukan penelitian lebih lanjut.

\section{DAFTAR PUSTAKA}

Harti, A.S. 2014. Mikrobiologi Kesehatan. Yogyakarta: Andi.

Kementerian Kesehatan Republik Indonesia. 2017. Data Dan Informasi Profil Kesehatan Indonesia 2017. http://www.pusdatin.kemkes.go.id/resourc es/download/pusdatin/profil-kesehatanindonesia/Data-dan-Informasi_ProfilKesehatan-Indonesia-2017.pdf

Menteri Kesehatan Republik Indonesia. 2012. Petunjuk Teknis Pemeriksaan Biakan, Identifikasi, dan Uji Kepekaan Mycobacterium tuberculosis pada Media Padat. Jakarta: Men.Kes.

Molnár, Z; Virág, E; and Ördög, V. 2011. Natural substances in tissue culture media of higher plants. Acta Biologica Szegediensis 55(1), 123-127. http://www.sci.uszeged.hu/ABS

Munawaroh, Hidayati dan Utami. 2015. Studi Komparasi Media Kultur Coco Blood Malachite Green (CBM) dengan Lowenstein Jensen (LJ) untuk Diagnosis Cepat, Spesifik, dan Sensitif pada Sputum Pasien Suspek Tuberkulosis. Majalah Kesehatan Fakultas Kedokteran Universitas Brawijaya. 2 (2). http://majalahfk.ub.ac.id/index.php/mkfku b/article/view/56

Palange, P; Narang, R and Kandi, V. 2016. Evaluation of Culture Media for Isolation of Mycobacterium Species from Human Clinical Specimens. Journal Curreus.8(8),

e757. https://www.ncbi.nlm.nih.gov/pmc/articles /PMC5045330/

Pollack, R; Findlay, L; Mondschein, W; and Modesto, R.R. 2016. Praktik Laboratorium Mikrobiologi, edisi ke 4. Indonesia: EGC.

Putri, B; Vickry. A, dan Maharani, H.W. 2013. Pemanfaatan Air Kelapa Sebagai Pengkaya Media Pertumbuhan Mikroalga Tetraselmis sp. Prosiding Semirata FMIPA Universitas Lampung, 2013 http://jurnal.fmipa.unila.ac.id/index.php/se mirata/article/viewFile/662/482.

Radji M. 2016. Buku Ajar Mikrobiologi Panduan Mahasiswa Farmasi Dan Kedokteran. Jakarta: EGC.

Sinaga H. 2011. Isolasi dan Identifikasi Mycobacterium tuberculosis Untuk Petugas Laboratorium. Palembang: Multi Sarana.

Soedarto. 2015. Mikrobiologi Kedokteran. Jakarta: Sagung Seto.

Yolanda, H dan Mulyana, Y. 2011. Uji Coba Penggunaan Limbah Air Kelpa Tua Sebagai Bahan Dasar Media Isolasi. Majalah Kedokteran Bandung 43(3):11721. http://journal.fk.unpad.ac.id/index.php/mk $\mathrm{b} /$ article/view/56

Zimbro, M.J; Power D.A; Miller, SM;Wilson, G.E; Johnson, J.A. 2009. Difco \& BBL Manual of Microbiological Culture Media: United States of America. 